\title{
ASO Visual Abstract: The Breast Cancer Patient Experience of Telemedicine During COVID-19
}

\section{Lina Cadili, MD ${ }^{1}$, Kristin DeGirolamo, MD, FRCSC ${ }^{1}$, Crystal Suet-Ying $\mathrm{Ma}^{2,3}$, Leo Chen, $\mathrm{MSc}^{4}$,} Elaine McKevitt, MD, FRCSC ${ }^{1,2}$, Jin-Si Pao, MD, FRCSC ${ }^{1,2}$, Carol Dingee, MD, FRCSC ${ }^{1,2}$, Amy Bazzarelli, MD, FRCSC ${ }^{1,2}$, and Rebecca Warburton, MD, FRCSC ${ }^{1,2}$

${ }^{1}$ Division of General Surgery, University of British Columbia, Vancouver, BC, Canada; ${ }^{2}$ Providence Breast Centre, Mount Saint Joseph Hospital, Vancouver, BC, Canada; ${ }^{3}$ Faculty of Science, University of British Columbia, Vancouver, BC, Canada; ${ }^{4}$ Faculty of Medicine, University of British Columbia, Vancouver, BC, Canada

In response to the COVID-19 pandemic, telemedicine has been adopted worldwide for the delivery of safe health care. A survey of breast cancer patients treated via tele- medicine in Vancouver yielded high satisfaction (https://d oi.org/10.1245/s10434-021-11103-w).

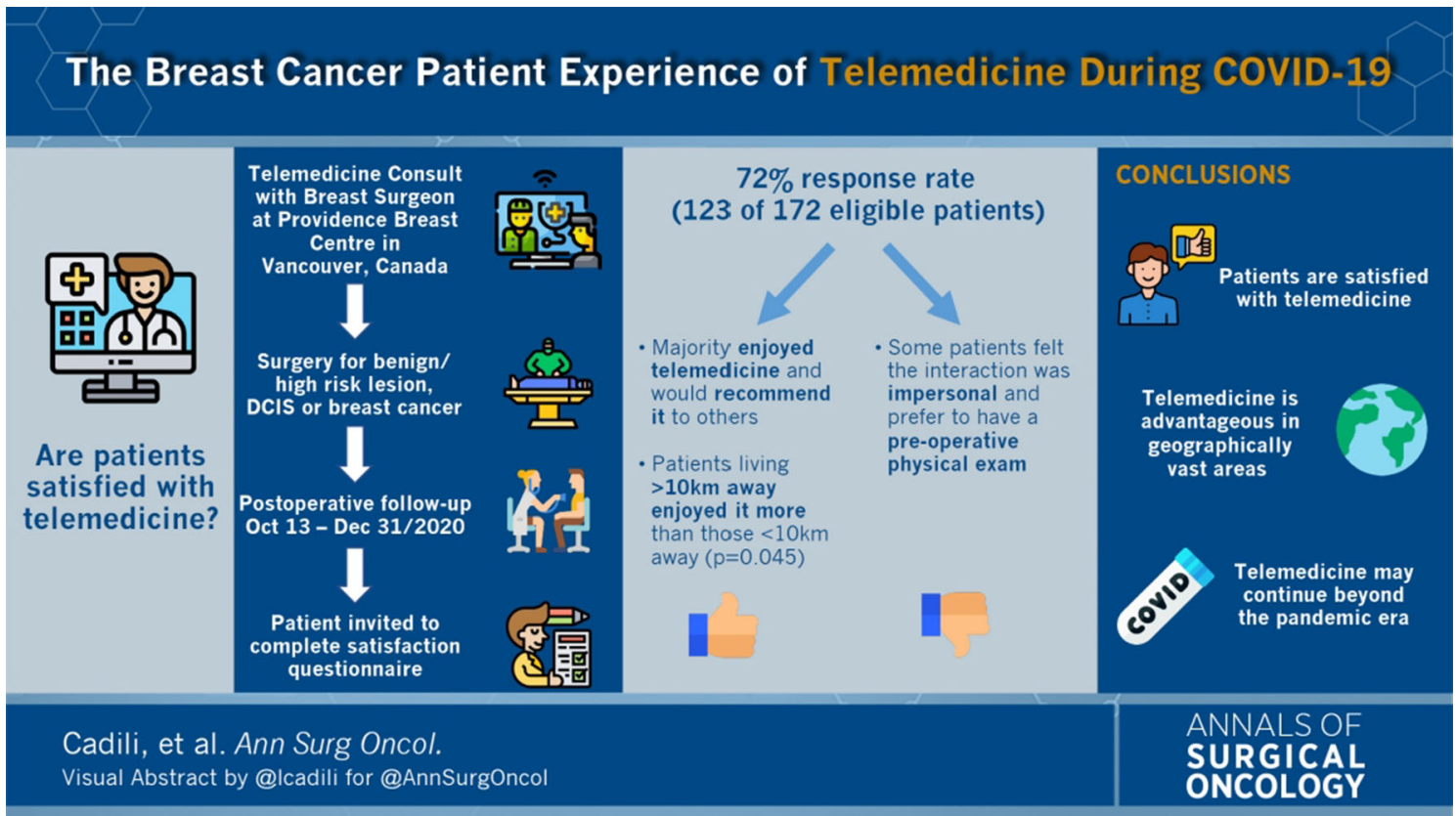

(C) Society of Surgical Oncology 2021

L. Cadili, MD

e-mail: lina.cadili@alumni.ubc.ca
DISCLOSURE There are no conflicts of interest.

Publisher's Note Springer Nature remains neutral with regard to jurisdictional claims in published maps and institutional affiliations. 